Article

\title{
Antibacterial and In Vivo Studies of a Green, One-Pot Preparation of Copper/Zinc Oxide Nanoparticle-Coated Bandages
}

\author{
Archana R. Deokar ${ }^{1}$, Ilana Perelshtein ${ }^{1}$, Melissa Saibene ${ }^{2}$, Nina Perkas ${ }^{1}$, Paride Mantecca ${ }^{2, *}$, \\ Yeshayahu Nitzan ${ }^{3}$ and Aharon Gedanken ${ }^{1, *(D)}$ \\ 1 Department of Chemistry, Bar-Ilan University, Ramat-Gan 52900, Israel; \\ archanadeokar84@gmail.com (A.R.D.); ch362@mail.biu.ac.il (I.P.); perkasn@mail.biu.ac.il (N.P.) \\ 2 Department of Earth and Environmental Sciences, Particulate Matter and Health Risk (POLARIS) Research \\ Centre, University of Milano, Bicocca, 20126 Milano, Italy; m.saibene2@campus.unimib.it \\ 3 The Mina and Everard Goodman Faculty of Life Sciences, Bar-Ilan University, Ramat-Gan 52900, Israel; \\ nitzay@biu.013.net.il \\ * Correspondence: paride.mantecca@unimib.it (P.M.); gedanken@mail.biu.ac.il (A.G.)
}

Citation: Deokar, A.R.;

Perelshtein, I.; Saibene, M.; Perkas, N.; Mantecca, P.; Nitzan, Y.; Gedanken, A. Antibacterial and In Vivo Studies of a Green, One-Pot Preparation of

Copper/Zinc Oxide

Nanoparticle-Coated Bandages

Membranes 2021, 11, 462.

https://doi.org/10.3390/

membranes11070462

Academic Editor: Ludomira

H. Granicka

Received: 9 May 2021

Accepted: 9 June 2021

Published: 22 June 2021

Publisher's Note: MDPI stays neutral with regard to jurisdictional claims in published maps and institutional affiliations.

Copyright: (c) 2021 by the authors. Licensee MDPI, Basel, Switzerland. This article is an open access article distributed under the terms and conditions of the Creative Commons Attribution (CC BY) license (https:// creativecommons.org/licenses/by/ $4.0 /)$.
Abstract: Simultaneous water and ethanol-based synthesis and coating of copper and zinc oxide $(\mathrm{CuO} / \mathrm{ZnO})$ nanoparticles (NPs) on bandages was carried out by ultrasound irradiation. High resolution-transmission electron microscopy demonstrated the effects of the solvent on the particle size and shape of metal oxide NPs. An antibacterial activity study of metal-oxide-coated bandages was carried out against Staphylococcus aureus (Gram-positive) and Escherichia coli (Gram-negative). $\mathrm{CuO}$ NP-coated bandages made from both water and ethanol demonstrated complete killing of S. aureus and E. coli bacteria within $30 \mathrm{~min}$., whereas $\mathrm{ZnO}$ NP-coated bandages demonstrated five-log reductions in viability for both kinds of bacteria after $60 \mathrm{~min}$ of interaction. Further, the antibacterial mechanism of $\mathrm{CuO} / \mathrm{ZnO}$ NP-coated bandages is proposed here based on electron spin resonance studies. Nanotoxicology investigations were conducted via in vivo examinations of the effect of the metal-oxide bandages on frog embryos (teratogenesis assay-Xenopus). The results show that waterbased coatings resulted in lesser impacts on embryo development than the ethanol-based ones. These bandages should therefore be considered safer than the ethanol-based ones. The comparison between the toxicity of the metal oxide NPs prepared in water and ethanol is of great importance, because water will replace ethanol for bulk scale synthesis of metal oxide NPs in commercial companies to avoid further ignition problems. The novelty and importance of this manuscript is avoiding the ethanol in the typical water:ethanol mixture as the solvent for the preparation of metal oxide NPs. Ethanol is ignitable, and commercial companies are trying the evade its use. This is especially important these days, as the face mask produced by sonochemistry (SONOMASK) is being sold all over the world by SONOVIA, and it is coated with $\mathrm{ZnO}$.

Keywords: ultrasound irradiation; water; ignition problem; $\mathrm{CuO} / \mathrm{ZnO} N P s$; antibacterial; in vivo

\section{Introduction}

The increasing resistance of bacteria towards conventional antibiotics strongly motivates designing effective antimicrobial agents to control mortality rates and hospital care costs [1,2]. For instance, methicillin-resistant Staphylococcus aureus (MRSA) alone caused 94,360 invasive infections occurred in the United States in 2005; these infections were associated with death in 18,650 cases [3]. Despite it being a nanotechnology era when it comes to conventional antibiotics, one can instead design robust antimicrobial materials to deal with the current scenario of antibacterial resistance. Hence, we consider it an urgent need to design a robust antimicrobial material to deal with the current scenario of antibacterial resistance. Based on nanotechnology, during the last few years several research groups 
put forth efforts to deal with the aforementioned antibacterial resistance [4-7]. Rotello and coworkers highlighted the multiple nanoparticle-based approaches to eliminate bacterial infections, providing crucial insights into the design of elements that play critical roles in creating antimicrobial nanotherapeutics. They focused on the pivotal role played by $\mathrm{NP}$-surface functionality in designing nanomaterials as self-therapeutic agents and delivery vehicles for antimicrobial cargo [8].

The antibacterial properties of organic and inorganic nanoparticles (NPs), and carbon based nanomaterials, including graphene, have been explored [9-16]. Among them, silver and semiconductor NPs, such as titanium dioxide and zinc oxide NPs, have been explored thoroughly [17-19]. Few NPs have been commercialized though, as toxicity issue of these NPs remains an unresolved issue [20]. The toxicity of NPs might arise as a result of the use of toxic chemicals during the synthesis processes. Additionally, the use of volatile organic solvents during bulk scale synthesis of NPs might lead to higher chances of accidental fires due to harsh experimental conditions, such as high temperatures. Practising green and sustainable chemistry for the synthesis of NPs would be optimal, as it would allow avoiding the use of hazardous chemicals as well [21]. Safer chemicals will lead to less toxicity and less chances of accidents during bulk scale synthesis. In our group, the ultrasound-assisted one-pot synthesis and deposition of magnesium fluoride, yttrium fluoride, chitosan, copper oxide/zinc oxide ( $\mathrm{CuO} / \mathrm{ZnO}) \mathrm{NPs}$ on cotton, catheters, polymer, glass, and teeth has been explored to study their antibacterial/antibiofilm properties [22-28]. Ultasound-assisted coating is green, efficient and cost effective, as it consumes less energy, solvent, and materials. Further coating is possible without the addition of any binder [29]. In sonochemistry, chemical effects of ultrasound arise from "acoustic cavitation," meaning continuous formation, growth, and implosive collapse of bubbles in the liquid, which creates an unusual chemical environment. "Cavitation" depends on several factors, such as the viscosity of the solvent and the ultrasonic intensity [22]. Physical and chemical properties of NPs can be enhanced with different morphologies of NPs by varying several of the aforementioned parameters, e.g., the solvent. Ali et al. studied the formation of nano/microparticles of vermiculite by varying different sonication conditions, such as the solvent, the reaction time, and the temperature [30].

In our previous study [31], we carried out ultrasound-assisted coating of metal oxide NPs onto cotton, which has been proven to be effective against multi-drug resitant bacterial strains. A solvent ratio of 90:10 ethanol:water (v:v) was employed for coating these NPs onto cotton bandages. This was performed in the course of an EC project called SONO in FP7. The commercial companies complained about the use of ethanol, which is an ignitable material and induces extra cost for its removal. Herein, we report the first successful coating of copper and zinc oxide NPs onto cotton using the universal solvent, water. This method will be beneficial economically and environmentally, since water is non-toxic and non-flammable. Water-based CuO NP-coated bandages were equally as effective as ethanolbased $\mathrm{CuO}$ NP-coated bandages for complete eradication of both S. aureus (Gram-positive) and Escherichia coli (Gram-negative) bacteria.

\section{Experimental}

\subsection{Deposition/Coating Procedure of $\mathrm{CuO} / \mathrm{ZnO} N P$ s on Bandages}

The coating of NPs on fabric was done using roll to roll sonochemical installation [32]. Copper/zinc acetates $(0.01 \mathrm{M})$ were dissolved in $400 \mathrm{~mL}$ of double distilled water $\left(\mathrm{ddH}_{2} \mathrm{O}\right)$. A 9/1 ethanol:water volume ratio solution was obtained after adding 3.6 L of ethanol. Please note that whenever we refer to ethanol solution it means ethanol:water 9:1 (v:v). In case of water synthesis, ethanol was replaced by $\mathrm{ddH}_{2} \mathrm{O}$. The solutions were heated and when a temperature of $60^{\circ} \mathrm{C}$ was reached, $7-10 \mathrm{~mL}$ of an aqueous solution of ammonium hydroxide (28-30\%) was injected into the reaction container to adjust the $\mathrm{pH}$ to $\sim 8$. At the end of the reaction, the color of the fabric changed from white to brown in the case of $\mathrm{CuO}$ NPs, whereas in case of ZnO NPs it remained white due to a curdy white precipitate of $\mathrm{ZnO}$ NPs. The coated bandages were cleaned with $\mathrm{ddH}_{2} \mathrm{O}$ and once with ethanol, 
and then dried under vacuum. Powders resulting from coated bandages were collected, dried, and subjected to further characterization.

\subsection{Characterization of $\mathrm{CuO} / \mathrm{ZnO} N P$ s and Bandages}

Powders obtained from roll to roll coatings of the corresponding metal oxide NPs were subjected to XRD (Bruker D8 diffractometer employs $\mathrm{Cu} \mathrm{K}$ alpha radiation). Morphologies and particle sizes of water/ethanol-based metal oxide NPs were observed by HR-TEM (high resolution transmission electron microscopy) (JEOL 2100, with accelerating voltage of $200 \mathrm{kV}$ ). Coated metal oxide weight percentages were analyzed by ICP (ion coupled plasma-ULTIMA 2). Dried metal-oxide-coated bandages were coated with conducting carbon and subjected to ESEM (FEI QUANTA 200F device) to confirm the uniform distribution of NPs on bandages. BET (Brunauer-Emmett-Teller) measurements were carried out as well.

\subsection{ESR Measurement}

ESR (electron spin resonance) coupled with a spin trap of 5,5-dimethyl-1-pyrroline$\mathrm{N}$-oxide (DMPO, Sigma, St. Louis, MO, USA) was employed to determine the reactive oxygen species (ROS) production abilities of water/ethanol-based $\mathrm{CuO} / \mathrm{ZnO} \mathrm{NP}$-coated bandages and the corresponding powders as well. Typically, for bandages, a $1.5 \times 1.5 \mathrm{~cm}^{2}$ piece of metal oxide NP-coated bandage was immersed in $180 \mu \mathrm{L}$ of double distilled water $\left(\mathrm{ddH}_{2} \mathrm{O}\right)$. Further, $20 \mu \mathrm{L}$ of DMPO was allowed to react with the bandages for $10 \mathrm{~min}$, and subsequently, $90 \mu \mathrm{L}$ of solution was withdrawn by a syringe into a gas-permeable Teflon capillary (Zeus Ind., Raritan, NJ, USA) with an inner diameter of $0.082 \mathrm{~cm}, 0.038$ inch wall thickness, and $15 \mathrm{~cm}$ length. Each capillary was folded twice, inserted into a narrow quartz tube open at both ends, and then placed in the ESR cavity. The ESR measurement conditions were as follows: $9.74 \mathrm{GHz}$ frequency; microwave power, $20 \mathrm{~mW}$; scan width, $65 \mathrm{G}$; resolution, 1024; receiver gain, $2 \times 10^{5}$; conversion time, $82 \mathrm{~ms}$; time constant, $655 \mathrm{~ms}$; sweep time, $84 \mathrm{~s}$; scans, 2; modulation frequency, $100 \mathrm{kHz}$. After acquisition of the data, the spectra were processed using Bruker WIN-EPR version 2.11 for baseline correction. The peak intensity, which is proportional to the amount of ROS, was calculated by double integration of the peak signals, and the intensity is expressed in arbitrary units.

A simulation of the recorded spectra was performed using an algorithm provided in WINSIM proGram, which is available from the NIEHS (National Institute of Environmental Health Sciences) at (http:/ / epr.niehs.nih.gov/pestmans/winsim.html).

\subsection{Colony Forming Unit Method (CFU)}

The antibacterial studies of $\mathrm{ZnO} / \mathrm{CuO} \mathrm{NP}$-coated bandages were evaluated by using the CFU method against $S$. aureus and E. coli bacterial strains. Overnight-cultured bacterial strains were transferred into a fresh Tryptic Soy Broth (TSB) medium and agitated for $4 \mathrm{~h}$ at $37^{\circ} \mathrm{C}$; then, $10^{8}$ cell cultures were harvested by centrifugation and washed with fresh $0.9 \%$ sodium chloride $(\mathrm{NaCl})$ solution. $\mathrm{ZnO} / \mathrm{CuO}$ coated bandages of $1.5 \times 1.5 \mathrm{~cm}$ were allowed to react with $2 \mathrm{~mL}$ of one bacterial strain for $60 \mathrm{~min}$. Aliquots of $200 \mu \mathrm{L}$ were taken out at different time intervals $(0,10,30 \mathrm{~min})$ and serially diluted with a fresh $0.9 \% \mathrm{NaCl}$ solution, and further plated onto agar for quantitation.

\subsection{In Vivo Toxicity Assay}

The toxicity of the differently coated bandages was assessed by the standard frog embryo teratogenesis assay using Xenopus (FETAX, ASTM, 1998), which was modified to allow embryos to stay in direct contact with the bandages. Embryos were incubated in contact with uncoated and coated bandages for $96 \mathrm{~h}$, from the blastula to the larval stage. The protocol used for this modified FETAX is briefly reported below. Adult Xenopus laevis were maintained in aquaria with dechlorinated tap water at a $22 \pm 2{ }^{\circ} \mathrm{C}$, in an alternating $12 \mathrm{~h}$ light/dark cycle, and were fed a semi-synthetic diet three times a week. The mating behavior of adult males and females was stimulated by Human Chorionic Gonadotropin 
(HCG) injection. After natural breeding, normally cleaved embryos at the blastula stage (stage 8 ), $5 \mathrm{~h}$ post-fertilization (hpf), were selected for testing, and after dejellying in $2.25 \%$ L-cysteine, 25 blastulae were placed in $8.0 \mathrm{~cm}$ glass petri dishes containing $30 \mathrm{~mL}$ of FETAX solution. On the bottom of each petri dish, the differently coated bandages to be tested were fixed, after being soaked for $15 \mathrm{~min}$ in Milli-Q water. All petri dishes were incubated in a thermostatic chamber at $23 \pm 0.5^{\circ} \mathrm{C}$ until the end of the test ( $96 \mathrm{hpf}$ ) in static conditions; each day the petri dishes were observed and dead embryos were removed. Mortality and malformation data were generated as endpoints of the assay. For each experimental group, the number of dead larvae was recorded; survivors were anaesthetized with $100 \mathrm{mg} / \mathrm{L}$ MS-222 and evaluated for single malformations under a dissection microscope. At the ends of the bioassays, surviving normal larvae were formalin fixed for growth retardation measurements. The number of malformed larvae was recorded, and body length (head to tail) was measured to derive the growth retardation effect. The assay was repeated at least three times under the same experimental conditions. The numbers of dead embryos versus their total numbers at the beginning of the tests led to the mortality percentages; and the numbers of malformed larvae versus the total numbers of surviving ones gave the malformed larva percentages. The relationship between the control and treated groups along with the percentages of dead and malformed larvae were investigated with Chisquare tests. To evaluate differences in growth retardation among groups, ANOVA was used. Statistical comparisons were considered to be significant at the $95 \%$ level $(p<0.05)$.

\section{Results and Discussion}

One of the motivations for the current study was the evaluation of the potential toxicity of metal oxide NPs of various shapes. From our observations, the solvent is one of the parameters that influences the shape and size of the sonochemically-produced metal oxide NPs. Therefore, the synthesis was carried out in a primarily ethanol solution or in water. The products obtained in water and ethanol-based synthesis were characterized by various techniques and compared; the results are presented below.

\subsection{Chemical Composition and Morphology}

The coatings of $\mathrm{CuO} / \mathrm{ZnO}$ NPs on cotton bandages were analyzed by ICP analysis. It is worth mentioning that bandages coated with metal oxide NPs using water as a solvent with equal molarities demonstrated larger amounts of coated material compared with ethanol equivalents. Equal amounts of metal oxide on bandages are essential for comparing bacterial killing efficiency. We found that water-based metal oxide NPs with initial precursor concentrations of $0.0050 \mathrm{M}$ (zinc acetate) and $0.0040 \mathrm{M}$ (copper acetate) demonstrated approximately equal weight percentages of metal oxide NP coatings corresponding to ethanol-based synthesis of metal oxide NPs with the initial precursor concentration of $0.01 \mathrm{M}$ (Table 1).

Table 1. Amounts of metal coated on the cotton fabric.

\begin{tabular}{cccc}
\hline $\begin{array}{c}\text { Precursor Concentration } \\
\text { (Molar) }\end{array}$ & Coated Bandages & $\mathbf{Z n O} \%$ & $\mathbf{C u O} \mathbf{~}$ \\
\hline 0.01 & $\mathrm{ZnO}$ in ethanol & 0.74 & 1.38 \\
\hline 0.01 & $\mathrm{CuO}$ in ethanol & - & - \\
\hline 0.0050 & $\mathrm{ZnO}$ in water & 0.71 & 1.50 \\
\hline 0.0040 & $\mathrm{CuO}$ in water & - &
\end{tabular}

$\mathrm{CuO} / \mathrm{ZnO}$ NP-coated bandages in water/ethanol were subjected to ESEM (Figure 1) to observe their morphologies, and they were compared with pristine bandages. Both water/ethanol synthesized $\mathrm{CuO} / \mathrm{ZnO} \mathrm{NP}$-coated bandages (Figure $1 \mathrm{~b}-\mathrm{e}$ ) demonstrated homogenous and dense coatings of metal oxides as compared to the smooth pristine bandages (Figure 1a-e). 


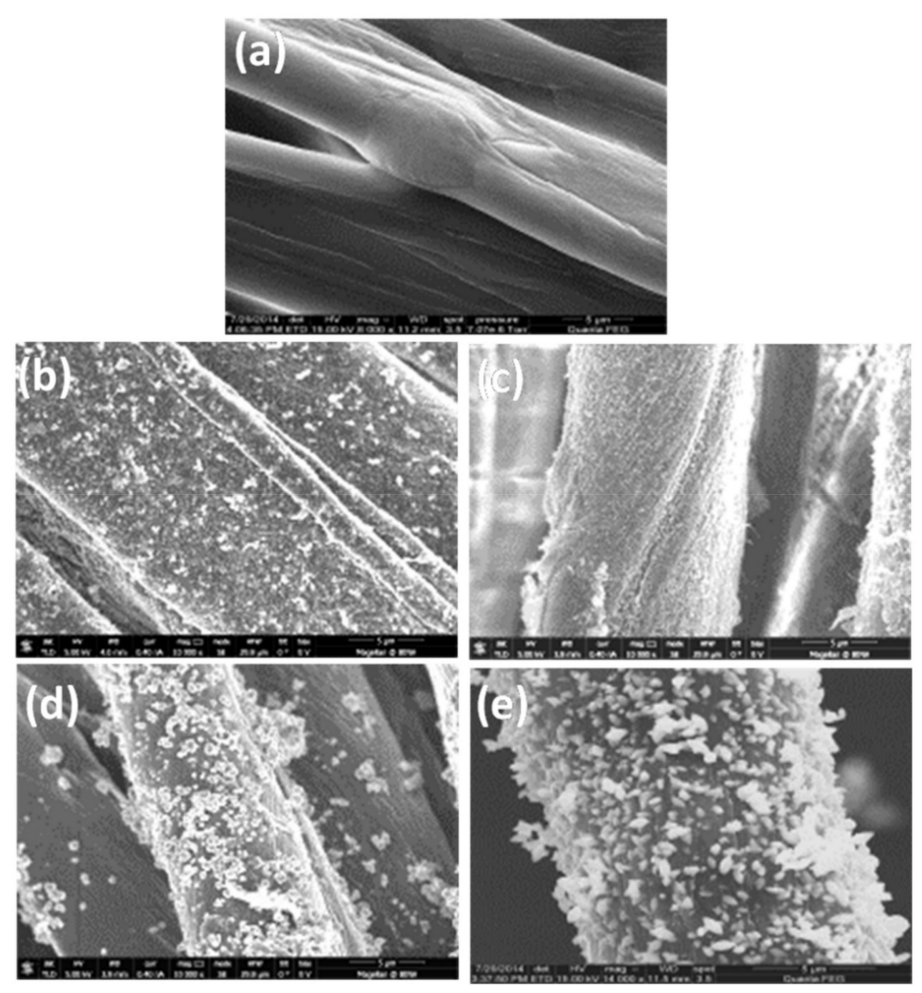

Figure 1. ESEM images of (a) pristine cotton, cotton fabric coated with $\mathrm{CuO}$ and $\mathrm{ZnO}$ NPs in ethanol $(\mathbf{b}, \mathbf{d})$ or in water $(\mathbf{c}, \mathbf{e})$; scale bar is $5 \mu \mathrm{m}$.

The $\mathrm{ZnO}$ and $\mathrm{CuO}$ NPs synthesized with water differ in shape and size compared with the products of ethanol-based synthesis. A detailed analysis of shapes and sizes of metal oxide NPs was carried out by HR-TEM. As expected, solvents played the major role in controlling the shapes and sizes of the metal oxide NPs. Figure 2 presents the HR-TEM images of $\mathrm{ZnO}$ and $\mathrm{CuO}$ NPs synthesized in water or in ethanol. The inset indicates SAED (selected area electron diffraction) of the NPs. All the synthesized NPs were crystalline, and a typical ring diffraction pattern was observed. The diffractions of each metal oxide match very well with the XRD result presented in Figure 2. Waterbased $\mathrm{ZnO}$ NPs (Figure 2a) demonstrated a rugby ball shape with an average length of $\sim 109 \mathrm{~nm}$ and a width of $\sim 70 \mathrm{~nm}$ (aspect ratio $\approx 1.5$ ). Ethanol-based ZnO NPs (Figure 2c) were rectangular in shape, and the average length and width were $\sim 270$ and $\sim 166 \mathrm{~nm}$, respectively; they had an aspect ratio of $\sim 1.6$. Leaf-like structure was observed for $\mathrm{CuO}$ NPs synthesized in water, and the average length and width were $\sim 113$ and $\sim 25 \mathrm{~nm}$, respectively; the aspect ratio was $\sim 4.52$ (Figure $2 \mathrm{~b}$ ). Aggregates of $\sim 130 \mathrm{~nm}$ were observed among ethanol-based $\mathrm{CuO}$ NPs, and the individual particle size was $\sim 7 \mathrm{~nm}$ (Figure $2 \mathrm{~d}$ ). $\mathrm{CuO}$ NPs synthesized in ethanol demonstrated a much smaller particle size compared with water-synthesized particles. It is clearly seen that the type of solvent during the hydrolysis of metal acetates has impacts on the shape and the size of the NPs. According to the BET method, the average surface areas for CuO NPs synthesized in ethanol and water were 76 and $51 \mathrm{~m}^{2} / \mathrm{g}$, respectively, whereas in case of ZnO NPs synthesized in ethanol and water, both average surface areas were $10 \pm 1 \mathrm{~m}^{2} / \mathrm{g}$. These similar values were due to the resemblance in size of the $\mathrm{ZnO}$ NPs fabricated by these solvents. BET results were in good agreement with HR-TEM results. 


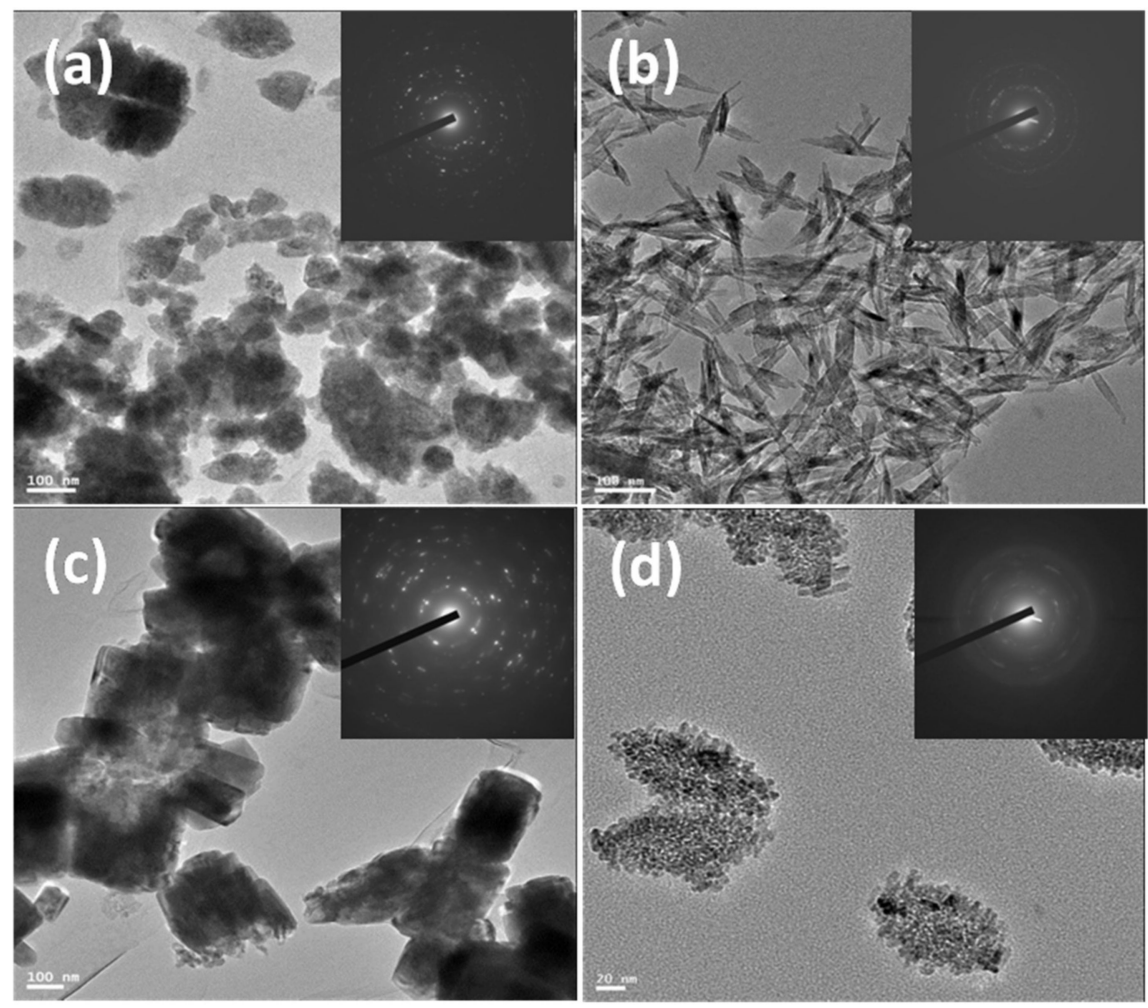

Figure 2. HR-TEM images of water-synthesized $\mathrm{ZnO}$ and $\mathrm{CuO}$ NPs (a,b); scale bar $100 \mathrm{~nm}$; (c,d) represent images of ethanol-based synthesized $\mathrm{ZnO}$ and $\mathrm{CuO}$ NPs, respectively; scale bars 100 and $20 \mathrm{~nm}$.

Figure 3 represents the XRD patterns of $\mathrm{CuO}$ and $\mathrm{ZnO}$ NPs synthesized in water and ethanol. The crystalline structure of neither zinc oxide nor copper oxide was influenced by the solvent used during the hydrolysis process. Identical reflection peaks were obtained in both solvents, and the peaks well match the patterns identified in the previous studies (PDF files 89-7102 and 80-1916) [29]. Moreover, even the intensities of the reflection peaks were similar for both solvents.

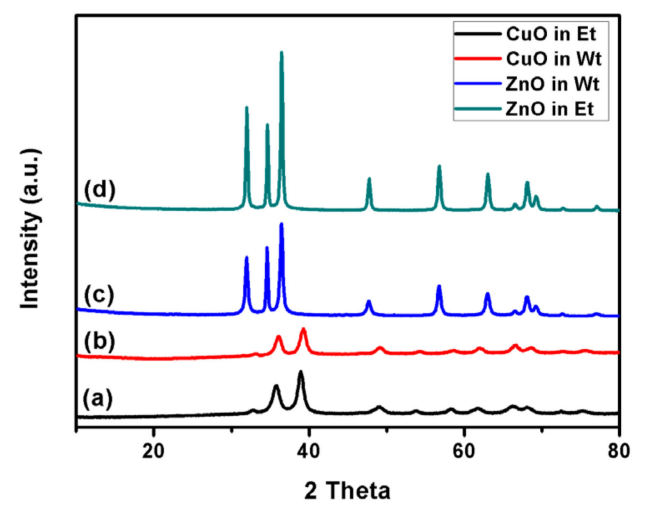

Figure 3. XRD spectra of CuO NPs synthesized in ethanol (a) or in water (b). ZnO NPs synthesized in water (c) or in ethanol (d).

\subsection{ESR Studies}

ROS production of NPs was determined by the ESR technique, while employing $\mathrm{DMPO}$ as a spin trap. Four resolved peaks generated from the DMPO-OH adduct identified the presence of hydroxyl radicals in the metal-oxide NP-coated bandages (Figure 4). 

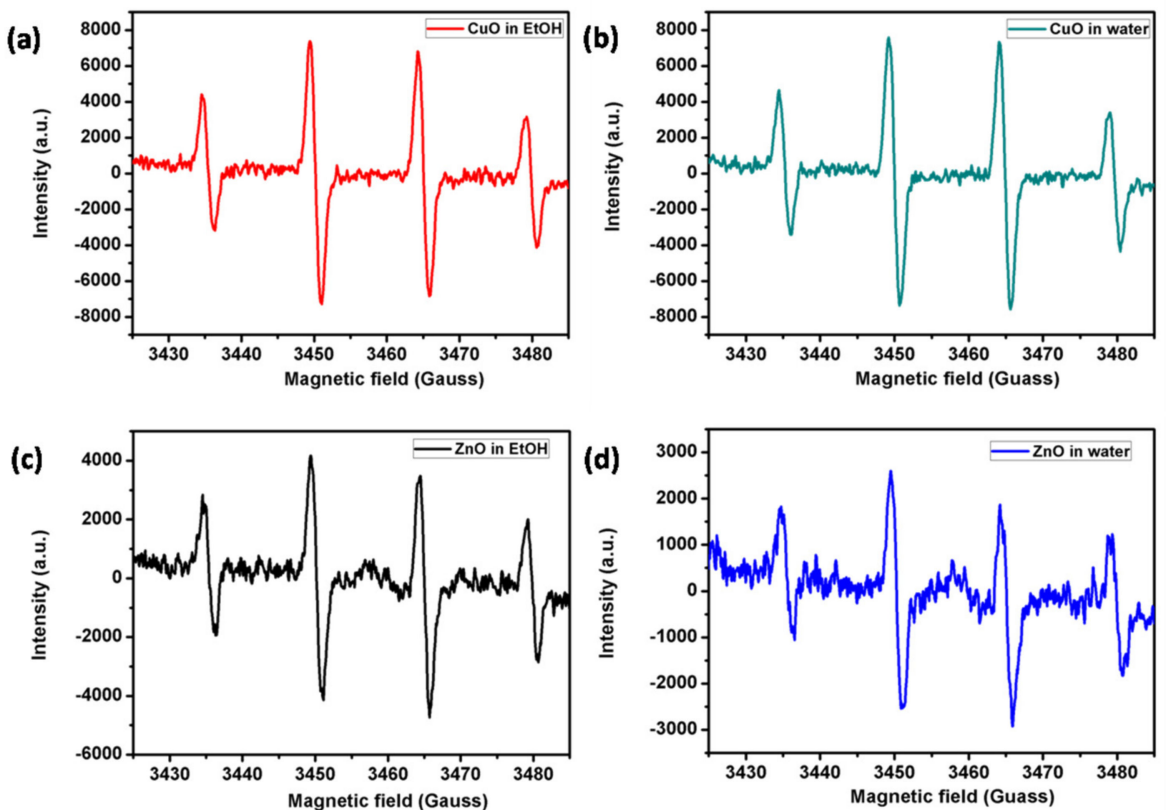

Figure 4. ROS generation by $\mathrm{CuO}$ and $\mathrm{ZnO}$ NP-coated bandages synthesized in ethanol $(\mathbf{a}, \mathbf{c})$ or water $(\mathbf{b}, \mathbf{d})$ in the presence of DMPO alone.

$\mathrm{CuO}$ NP-coated bandages (Figure 4a,b) made in water or ethanol gave rise to more intense peaks compared to $\mathrm{ZnO} \mathrm{NP}$-coated bandages made in either water or ethanol (Figure 4); this was due to CuO NPs being smaller particles compared to ZnO NPs (Figure 2). Smaller particles possess greater surface area to volume ratios, and hence induce more ROS production. ESR studies were in good accordance with BET and antibacterial studies. ZnO NPs synthesized in water or ethanol demonstrated weak ESR signals, indicating a poor ability to generate hydroxyl radicals.

\subsection{Antibacterial Studies}

Figure 5 represents antibacterial activity for water and ethanol-based synthesized $\mathrm{ZnO}$ and $\mathrm{CuO}$ NP-coated bandages. In the case of $\mathrm{CuO}$ NP-coated bandages, considering both water and ethanol, complete eradication of both S. aureus and E. coli bacteria was observed within $30 \mathrm{~min}$. (Figure 5a,c), whereas in $60 \mathrm{~min}$, ZnO NP-coated bandages (water or ethanol-based) revealed only 5-log reductions for both bacterial strains (Figure 5b,d). The antibacterial activities of the coated bandages are in accordance with the ESR and BET studies. CuO NPs are smaller; i.e., they have more surface area compared to ZnO NPs, and hence better antibacterial activity. Herein we demonstrate that better ROS production by $\mathrm{CuO}$ NPs could lead to better antibacterial activity compared to ZnO NPs.

Commercialization of $\mathrm{CuO}$ and $\mathrm{ZnO} \mathrm{NP}$-coated bandages requires in vivo or vitro toxicity screening. Hence, we have carried out an in vivo toxicity study of bandages using the FETAX (ASTM, 1998) standard, which we modified to allow embryos to stay in direct contact with the bandages. Embryos (Figure 6, stage 8) were incubated in contact with uncoated and coated bandages for $96 \mathrm{~h}$ from the blastula to the larval stage. Very little, non-significant embryo lethality was observed for all the bandages screened, except the ethanol-based $\mathrm{CuO} \mathrm{NP}(\mathrm{E}-\mathrm{CuO}$ ) coated bandages (Figure 6). Only E-CuO showed a significant difference in lethality (Table 2). 

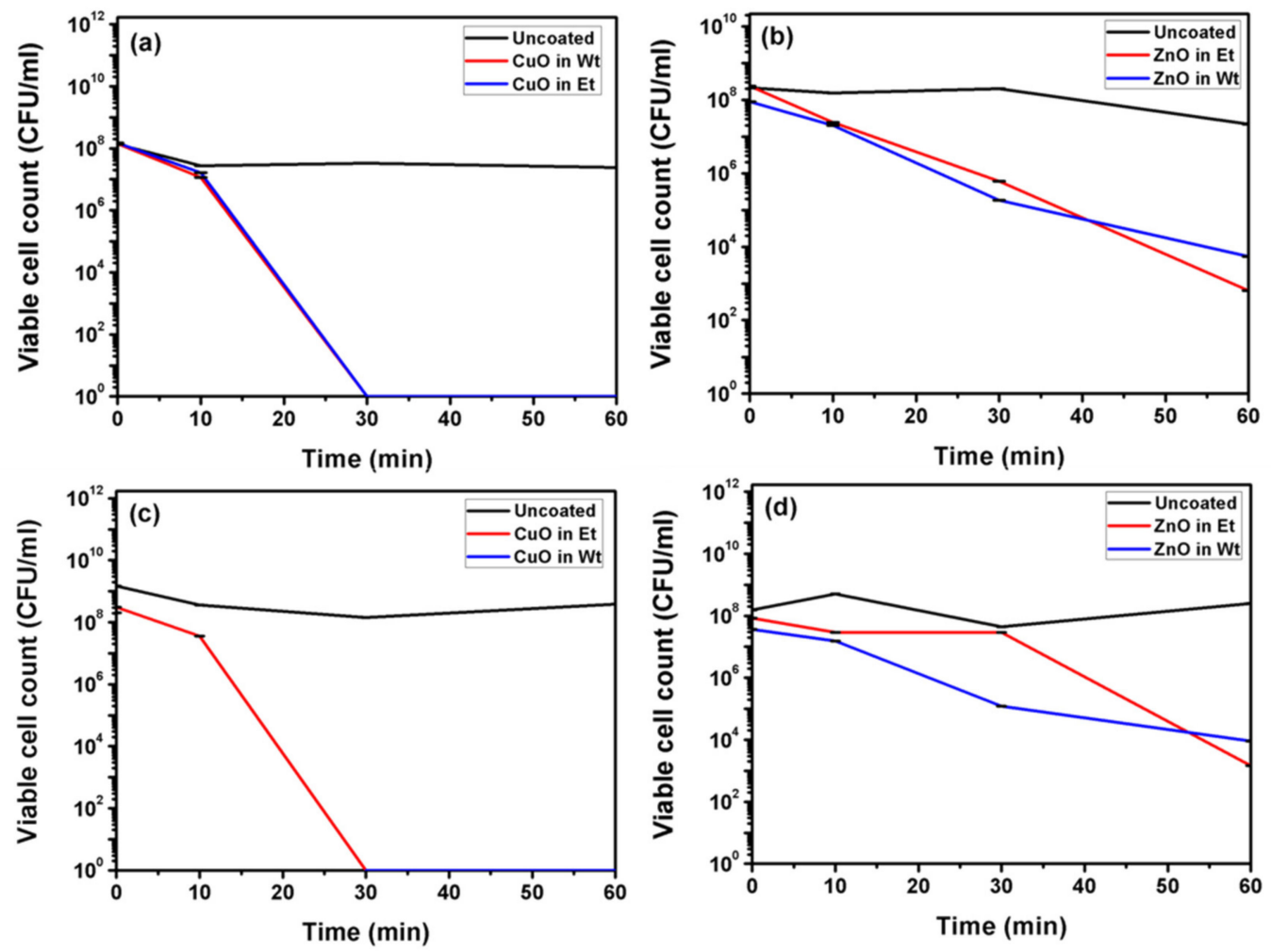

Figure 5. Antibacterial studies of $\mathrm{CuO}$ and $\mathrm{ZnO} \mathrm{NP}$-coated bandages in water or ethanol against S. aureus (Gram-positive) $(\mathbf{a}, \mathbf{b})$ and E. coli (Gram-negative) (c,d).

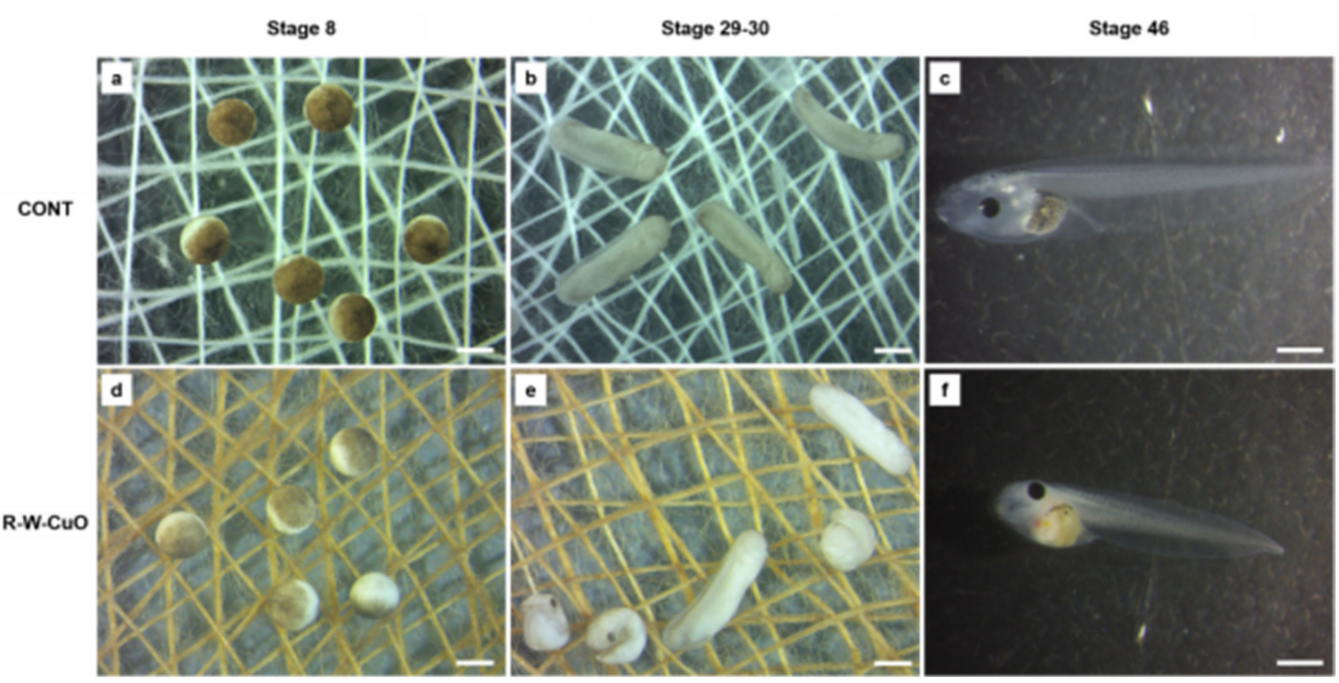

Figure 6. Stereomicroscopic images showing the experimental set up, with embryos in direct contact with uncoated cotton bandages $(\mathbf{a}, \mathbf{b})$ and $\mathrm{CuO} N$ P-coated bandages in water $(\mathrm{W}-\mathrm{CuO})(\mathbf{d}, \mathbf{e})$, fixed at the bottom of glass petri dishes. Embryos were photographed at the beginning (stage 8) (a,d) and at the middle (stage 29-30 of the test). Larvae at the end of the test (stage 46) were screened for single malformations: (c), control larva; (f), W-CuO exposed larva showing irregular gut and body length shortening. Bars $=1 \mathrm{~mm}$.

All bandages significantly increased the malformation percentage in exposed embryos. Regardless, the percentage of malformed embryos for most of the types of coated bandages was lower than $40 \%$, testifying to a weak teratogenic capacity. Indeed, our results were below the $\mathrm{EC}_{50}$ (effective concentration for $50 \%$ of the embryos used), which is usually 
combined with the $\mathrm{LC}_{50}$ (lethal concentration for the $50 \%$ of the embryos used) for calculating the teratogenic index. Only embryos grown in contact with ethanol-based $\mathrm{ZnO}$ coated bandages showed a high malformation percentage $(71.3 \%)$, a value significantly higher than those of the corresponding water-based $\mathrm{ZnO}$ or $\mathrm{CuO}$ NP-based coatings (Table 2). The embryo growth retardation effects were significant and comparable in all the treatment groups, confirming that all the materials used exert baseline toxicity toward developing Xenopus embryos, in line with previous studies (Figure 7) [33].

Table 2. Embryotoxic effects in X. laevis.

\begin{tabular}{cccccc}
\hline & \multicolumn{5}{c}{ Bandages } \\
\hline & Control & W-ZnO & E-ZnO & W-CuO & E-CuO \\
\hline Utilized embryos (n) & 151 & 124 & 151 & 122 & 126 \\
\hline Dead embryos (n) & 2 & 6 & 1 & 6 & 20 \\
\hline Mortality (\%) & 1.3 & 4.8 & $0.7^{\circ}$ & 4.9 & $15.9^{* * \circ}$ \\
\hline Living larvae (n) & 149 & 118 & 150 & 116 & 106 \\
\hline Malformed larvae (n) & 5 & 30 & $107^{* *}$ & 43 & 39 \\
\hline Malformed larvae (\%) & $3.4^{* *}$ & $25.4^{* *}$ & $71.3^{* *}$ & $37.1^{* *}$ & $36.8^{* *}$
\end{tabular}

** Chi square test; $p<0.001$ vs Control, ${ }^{\circ}$ Chi square test; $p<0.05$ water vs. ethanol for the same metal oxide NPs.

${ }^{\circ}$ Chi square test; $p<0.001$ water vs. ethanol for the same metal oxide NPs.

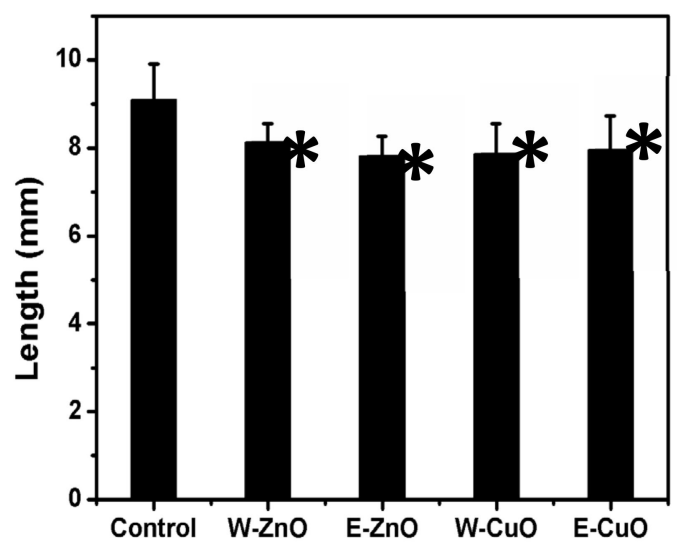

Figure 7. Growth retardation effects in embryos exposed to water or ethanol-based $\mathrm{ZnO}$ and $\mathrm{CuO}$ NP-coated bandages. ${ }^{*}$ Statistically different from the control (ANOVA, $p<0.05$ ).

In conclusion, according to the present results, water-based metal oxide NP-based coatings are less harmful to embryo development; in particular, we did see rescued embryo mortality with the $\mathrm{CuO}$ coating and rescued embryo malformation with $\mathrm{ZnO}$ bandages, which allows us to consider water-based bandages as safer than ethanol-based ones. Our in vivo studies are in accordance with ESR (Figure 4): ethanol-based metal-oxide-coated NPs gave rise to an intense hydroxyl radical signal compare to water-based metal-oxidecoated NPs. The involvement of ROS has been previously demonstrated in sonochemically synthesized $\mathrm{ZnO}$ NP-induced toxicity [34]. This evidence was obtained by exposing Xenopus embryos to $\mathrm{ZnO}$ and $\mathrm{CuO}$ NPs synthesized in ethanol, and even in that case, only $\mathrm{ZnO}$ NPs induced embryo malformation. Diffraction patterns (Figure 2) of both water and ethanol-based synthesized ZnO NPs demonstrated a hexagonal crystal structure, so the possibility of adverse effects due to the chemical structure of ZnO NPs can be neglected. Additionally, considering that such adverse effects have been attributed to the direct contact between embryo tissues and NPs, rather than Zn ions' dissolution [35], it is possible to hypothesize that the higher toxicity induced by ethanol ZnO NPs may be dependent on the peculiar physical structure, which leads to ROS production once in contact with biological 
tissues. Of course, this aspect, as well as the specific contribution to toxicity of the dissolved ions, merits further experimental efforts.

\section{Conclusions}

In conclusion, one-pot synthesis of $\mathrm{CuO}$ and $\mathrm{ZnO} N \mathrm{NP}$ coatings on fabrics was successfully performed in water for the first time. $\mathrm{CuO} \mathrm{NP}$-coated bandages in water or ethanol were found to be more effective against both S. aureus and E. coli compared to ZnO NP-coated ones. Herein, our study demonstrated that ethanol can be replaced by water for the synthesis of metal-oxide NPs. This could be a great way to avoid ignition accidents during bulk scale synthesis of metal-oxide NPs in commercial companies. Moreover, on the basis of in vivo studies of $\mathrm{CuO} / \mathrm{ZnO} \mathrm{NP}$-coated bandages against FETAX, we conclude that water-based metal-oxide-coated bandages were less toxic compared to ethanol-based ones. Hence, these coated bandages could bring about a revolution in combating hospital acquired infections, and hence might contribute to a lower mortality rate and lower hospital care costs.

Author Contributions: A.R.D., I.P., N.P., Y.N., A.G.-Synthesis, coating, characterization and antibacterial properties. M.S., P.M.-Toxicology studies. All authors have read and agreed to the published version of the manuscript.

Funding: This work was funded by the European Community's Horizon 2020 Framework Program H2020 (H2020-720851 project PROTECT-Pre-commercial lines for production of surface nanostructured antimicrobial and anti-biofilm textiles, medical devices, and water treatment membranes) (www.protect-h2020.eu).

Acknowledgments: The proposed study was supported by Fondazione Cariplo [OverNanotox 2013-0987 to P.M., Italy.

Conflicts of Interest: The authors of this manuscript do not have any conflict of interest with any scientific institution or with any scientists.

\section{References}

1. Andersson, D.I.; Hughes, D. Antibiotic resistance and its cost: Is it possible to reverse resistance? Nat. Rev. Microbiol. 2010, 8, 260. [CrossRef] [PubMed]

2. Kang, C.I.; Kim, S.H.; Park, W.B.; Lee, K.D.; Kim, H.B.; Kim, E.C.; Oh, M.D.; Choe, K.W. Bloodstream infections caused by antibiotic-resistant gram-negative bacilli: Risk factors for mortality and impact of inappropriate initial antimicrobial therapy on outcome. Antimicrob. Agents Chemother. 2005, 49, 760. [CrossRef] [PubMed]

3. Klevens, R.M.; Morrison, M.A.; Nadle, J.; Petit, S.; Gershman, K.; Ray, S.; Harrison, L.H.; Lynfield, R.; Dumyati, G.; Townes, J.M.; et al. Invasive methicillin-resistant Staphylococcus aureus infections in the United States. JAMA 2007, 298, 1763. [CrossRef] [PubMed]

4. Zhao, Y.; Tian, Y.; Cui, Y.; Liu, W.; Ma, W.; Jiang, X. Small Molecule-Capped Gold Nanoparticles as Potent Antibacterial Agents That Target Gram-Negative Bacteria. J. Am. Chem. Soc. 2010, 132, 12349-12356. [CrossRef]

5. Gao, J.; Li, C.; Zhou, J.; Lu, L.; Zhao, C.; Zhu, Y. Plasma sprayed alumina-nanosilver antibacterial coatings. RSC Adv. 2015, 5, 20357. [CrossRef]

6. Zhou, Y.; Jiang, X.; Tang, J.; Su, Y.; Peng, F.; Lu, Y.; Peng, R.; He, Y. A silicon-based antibacterial material featuring robust and high antibacterial activity. J. Mater. Chem. B 2014, 2, 691. [CrossRef]

7. Wei, L.; Wang, H.; Wang, Z.; Yu, M.; Chen, S. Preparation and long-term antibacterial activity of $\mathrm{TiO}_{2}$ nanotubes loaded with $\mathrm{Ag}$ nanoparticles and Ag ions. RSC Adv. 2015, 5, 74347. [CrossRef]

8. Gupta, A.; Mumtaz, S.; Li, C.H.; Hussain, I.; Rotello, V.M. Combatting antibiotic-resistant bacteria using nanomaterials. Chem. Soc. Rev. 2019, 48, 415-427. [CrossRef]

9. Banerjee, I.; Mondal, D.; Martin, J.; Kane, R.S. Photoactivated antimicrobial activity of carbon nanotube-porphyrin conjugates. Langmuir 2010, 26, 17369. [CrossRef]

10. Butchosa, N.N.; Brown, C.; Larsson, P.T.; Berglund, L.A.; Bulone, V.; Zhou, Q. Nanocomposites of bacterial cellulose nanofibers and chitin nanocrystals: Fabrication, characterization and bactericidal activity. Green Chem. 2013, 15, 3404. [CrossRef]

11. Petkova, P.; Francesko, A.; Fernandes, M.M.; Mendoza, E.; Perelshtein, I.; Gedanken, A.; Tzanov, T. Sonochemical coating of textiles with hybrid $\mathrm{ZnO} /$ chitosan antimicrobial nanoparticles. ACS Appl. Mater. Interf. 2014, 6, 1164. [CrossRef]

12. Gedda, G.; Pandey, S.; Lin, Y.C.; Wu, H.F. Antibacterial effect of calcium oxide nano-plates fabricated from shrimp shells. Green Chem. 2015, 17, 3276. [CrossRef]

13. Tian, T.; Shi, X.; Cheng, L.; Luo, Y.; Dong, Z.; Gong, H.; Xu, L.; Zhong, Z.; Peng, R.; Liu, Z. Graphene-based nanocomposite as an effective, multifunctional, and recyclable antibacterial agent. ACS Appl. Mater. Interf. 2014, 6, 8542. [CrossRef] 
14. Wu, M.C.; Deokar, A.R.; Liao, J.H.; Shih, P.Y.; Ling, Y.C. Graphene-based photothermal agent for rapid and effective killing of bacteria. ACS Nano 2013, 7, 1281. [CrossRef]

15. Deokar, A.R.; Lin, L.Y.; Chang, C.C.; Ling, Y.C. Single-walled carbon nanotube coated antibacterial paper: Preparation and mechanistic study. J. Mater. Chem. B 2013, 1, 2639. [CrossRef]

16. Chen, H.; Wang, B.; Gao, D.; Guan, M.; Zheng, L.; Ouyang, H.; Zhao, Z.; Feng, W. Broad-spectrum antibacterial activity of carbon nanotubes to human gut bacteria. Small 2013, 9, 2735. [CrossRef]

17. Tobaldi, D.M.; Piccirillo, C.; Pullar, R.C.; Gualtieri, A.F.; Seabra, M.P.; Castro, P.M.L.; Labrincha, J.A. Silver-Modified Nano-titania as an Antibacterial Agent and Photocatalyst. J. Phys. Chem. C 2014, 9, 4751. [CrossRef]

18. He, W.; Kim, H.K.; Wamer, W.G.; Melka, D.; Callahan, J.H.; Yin, J.J. Photogenerated charge carriers and reactive oxygen species in $\mathrm{ZnO} / \mathrm{Au}$ hybrid nanostructures with enhanced photocatalytic and antibacterial activity. J. Am. Chem. Soc. 2014, 136, 750. [CrossRef]

19. Cha, S.H.; Hong, J.; McGuffie, M.; Yeom, B.; Van Epps, J.S.; Kotov, N.A. Shape-Dependent Biomimetic Inhibition of Enzyme by Nanoparticles and Their Antibacterial Activity. ACS Nano 2015, 9, 9097. [CrossRef]

20. Hansen, S.F.; Baun, A. When enough is enough. Nat. Nanotechnol. 2012, 7, 409. [CrossRef]

21. Sheldon, R.A. Green solvents for sustainable organic synthesis: State of the art. Green Chem. 2005, 7, 267. [CrossRef]

22. Applerot, G.; Abu-Mukh, R.; Irzh, A.; Charmet, J.; Keppner, H.; Laux, E.; Guibert, E.; Gedanken, A.A. Decorating parylene-coated glass with $\mathrm{ZnO}$ nanoparticles for antibacterial applications: A comparative study of sonochemical, microwave, and microwaveplasma coating routes. ACS Appl. Mater. Interf. 2010, 2, 1052. [CrossRef] [PubMed]

23. Lellouche, J.; Friedman, A.; Lahmi, R.; Gedanken, A.; Banin, E. Antibiofilm surface functionalization of catheters by magnesium fluoride nanoparticles. Int. J. Nanomed. 2012, 7, 1175.

24. Perelshtein, I.; Applerot, G.; Perkas, N.; Wehrschuetz-Sigl, E.; Hasmann, A.; Guebitz, G.; Gedanken, A. CuO-cotton nanocomposite: Formation, morphology, and antibacterial activity. Surf. Coat. Technol. 2009, 204, 54. [CrossRef]

25. Perelshtein, I.; Ruderman, E.; Perkas, N.; Tzanov, T.; Beddow, J.; Joyce, E.; Mason, T.J.; Blanes, M.; Molla, K.; Patolla, A.; et al. Chitosan and chitosan-ZnO-based complex nanoparticles: Formation, characterization, and antibacterial activity. J. Mater. Chem. B 2013, 1, 1968. [CrossRef]

26. Eshed, M.; Lellouche, J.; Matalon, S.; Gedanken, A.; Banin, E. Sonochemical coatings of ZnO and CuO nanoparticles inhibit streptococcus mutans biofilm formation on teeth model. Langmuir 2012, 28, 12288. [CrossRef]

27. Shimanovich, U.; Cavaco-Paulo, A.; Nitzan, Y.; Gedanken, A. Sonochemical coating of cotton and polyester fabrics with "antibacterial" BSA and casein spheres. Chem. A Eur. J. 2012, 18, 365. [CrossRef]

28. Perelshtein, I.; Applerot, G.; Perkas, N.; Wehrschetz-Sigl, E.; Hasmann, A.; Guebitz, G.M.; Gedanken, A. Antibacterial properties of an in situ generated and simultaneously deposited nanocrystalline ZnO on fabrics. ACS Appl. Mater. Interf. $2009,1,361$. [CrossRef]

29. Ghule, K.; Ghule, A.V.; Chen, B.J.; Ling, Y.C. Preparation and characterization of ZnO nanoparticles coated paper and its antibacterial activity study. Green Chem. 2006, 8, 1034-1041. [CrossRef]

30. Malka, E.; Perelshtein, I.; Lipovsky, A.; Shalom, Y.; Naparstek, L.; Perkas, N.; Patick, T.; Lubart, R.; Nitzan, Y.; Banin, E.; et al. Eradication of multi-drug resistant bacteria by a novel Zn-doped CuO nanocomposite. Small 2013, 9, 4069. [CrossRef]

31. Perelshtein, I.; Lipovsky, A.; Perkas, N.; Tzanov, T.; Arguirova, M.; Leseva, M.; Gedanken, A. Making the hospital a safer place by sonochemical coating of all its textiles with antibacterial nanoparticles. Ultrason. Sonochem. 2015, 25, 82. [CrossRef] [PubMed]

32. Ali, F.; Reinert, L.; Levêque, J.M.; Duclaux, L.; Muller, F.; Saeed, S.; Shah, S.S. Effect of sonication conditions: Solvent, time, temperature and reactor type on the preparation of micron sized vermiculite particles. Ultrason. Sonochem. 2013, $21,1002$. [CrossRef] [PubMed]

33. Bacchetta, R.; Santo, N.; Fascio, U.; Moschini, E.; Freddi, S.; Chirico, G.; Camatini, M.; Mantecca, P. Nano-sized CuO, TiO 2 and $\mathrm{ZnO}$ affect Xenopus laevis development. Nanotoxicology 2011, 6, 381. [CrossRef] [PubMed]

34. Mantecca, P.; Moschini, E.; Bonfanti, P.; Fascio, U.; Perelshtein, I.; Lipovsky, A.; Chirico, G.; Bacchetta, R.; Del Giacco, L.; Colombo, A.; et al. Toxicity Evaluation of a New Zn-Doped CuO Nanocomposite with Highly Effective Antibacterial Properties. Toxicol. Sci. 2015, 146, 16. [CrossRef]

35. Bacchetta, R.; Moschini, E.; Santo, N.; Fascio, U.; Del Giacco, L.; Freddi, S.; Camatini, M.; Mantecca, P. Evidence and uptake routes for Zinc oxide nanoparticles through the gastrointestinal barrier in Xenopuslaevis. Nanotoxicology 2014, 8, 728. 